\title{
GALICIA PERANTE O RETO DA AUTOMATIZACIÓN DO TRABALLO
}

Juan Ramón GARCÍA

BBVA Research

Resumo: A partir das probabilidades de automatización de cada ocupación calculadas por Frey e Osborne (2017), utilízanse os microdatos da mostra anual da EPA entre 2011 e 2016 para determinar as características persoais e laborais que condicionan o risco de que un traballador en Galicia sexa substituído por una máquina. Os resultados das estimacións amosan que a probabilidade de automatización diminúe co grao de responsabilidade, o nivel educativo, a disposición a participar en accións formativas e a adopción de novas formas de traballo, como o teletraballo, e é comparativamente reducida para os ocupados en educación, sanidade, servizos sociais, TIC, enerxía e actividades artísticas ou científico-técnicas. As restantes características do traballador e da empresa xogan un papel secundario para explicar o risco de dixitalización. Co obxectivo de atenuar as repercusións negativas do progreso tecnolóxico sobre o emprego e acadar un crecemento inclusivo, é imprescindible que os axentes económicos, tanto públicos como privados, gobernen o cambio. Para acadalo, é preciso actuar en dous ámbitos estreitamente relacionados: a educación e o mercado de traballo.

Palabras chave: cambio tecnolóxico, automatización, educación, emprego, políticas públicas

Clasificación JEL: E24, J24, J31, J62, O33

\section{Introdución}

Igual que nas revolucións industriais precedentes, o proceso de transformación tecnolóxica en curso terá consecuencias disruptivas para o mercado de traballo. Porén, o desenlace destas repercusións suscita certa polémica. Algúns autores afirman que a automatización de tarefas impulsada pola Cuarta Revolución Industrial causará unha destrución masiva do emprego ${ }^{1}$. Opinan que os novos postos de traballo que o cambio tecnolóxico contribuirá a xerar non serán suficientes para absorber a oferta de man de obra e que, ademais, a calidade do emprego dispoñible se verá negativamente afectada. Con iso, defenden, producirase unha diminución a longo prazo da participación do traballo no ingreso que creará gañadores e perdedores.

Outros autores, en cambio, aseguran que a visión sombriza da robotización como destrutora de emprego débese á dificultade para anticipar a aparición de novas ocupacións ${ }^{2}$. Se ben recoñecen que a automatización se materializará nun proceso de destrución creativa -como nas revolucións industriais anteriores-, opinan que os efectos netos serán positivos. Estes autores basean a súa visión nos beneficios económicos contrastados das novas tecnoloxías. Estas permiten reducir os custos de produción e os prezos finais, e aumentar a calidade e diversidade dos produtos, o que podería contribuír a incentivar o consumo e a creación de emprego ${ }^{3}$.

Malia que este proceso de destrución creativa non constitúe un aspecto sobranceiro do cambio tecnolóxico actual, a velocidade que está acadando a actividade innovadora si que o é, e ameaza con abreviar o percorrido cara un novo equilibrio entre a oferta e a demanda

\footnotetext{
1 Véxanse Avent (2017), Frey e Osbourne (2017), Acemoglu e Restrepo (2017), entre outros.

2 Véxanse, por exemplo, Moretti (2010), Mokyr, Vickers e Ziebarth (2015), Gregory, Salomons e Zierahn (2016) e Graetz e Michaels (2018).

3 Unha revisión detallada da literatura pódese consultar en Doménech et al. (2018).
} 
de emprego. Como consecuencia, a identificación dos traballadores máis vulnerables á revolución dixital é unha condición necesaria para minimizar os custos de transición individuais e sociais. Para iso, este artigo utiliza as probabilidades de automatización de cada ocupación, obtidas por Frey e Osborne (2017), para determinar as características persoais e laborais que condicionan o risco de que un traballador en Galicia, en particular, e en España, en xeral, perda o seu emprego como consecuencia da disrupción tecnolóxica.

Os resultados suxiren que ata un 38\% dos postos de traballo en Galicia estaría en risco elevado de ser computarizado, 2 puntos por enriba do conxunto de España. Ademais, estímase que a probabilidade de automatización é maior para os empregados sen cargos de responsabilidade, ocupados na agricultura, o comercio, a hostalería, a industria manufactureira ou as actividades financeiras e inmobiliarias, con baixo nivel educativo e con menor disposición a participar en accións formativas ou a adoptar novas formas de traballo. As restantes características do traballador -como o xénero, a idade, a antigüidade, o tipo de contrato e a situación laboral de procedencia- e da empresa -como o tamaño- xogan un papel secundario para explicar o risco de automatización.

O resto do artigo estrutúrase como segue. Na segunda sección realízase unha análise descritiva das características dos empregados en Galicia e España en función da automatización agardada das súas ocupacións. Na sección 3 preséntanse os resultados dunha análise de regresión que identifica os factores detrás da probabilidade de computarización. Por último, na sección 4, discútense as principais conclusións e recoméndanse algunhas medidas de política económica.

\section{Caracterización dos traballadores conforme ao risco de automatización da súa ocupación}

Esta sección realiza unha primeira aproximación aos colectivos máis expostos á revolución dixital. Para iso, utilízanse as probabilidades de computarización de cada ocupación estimadas por Frey e Osborne 4 (2017) e os microdatos da mostra anual da Enquisa de Poboación Activa (EPA) entre 2011 e 2016.

A partir da información a tres díxitos da Clasificación Nacional de Ocupacións (CNO2011) e logo de atribuír a cada ocupado da EPA a probabilidade de automatización da ocupación que desempeña ${ }^{5}$, obtense que o $38 \%$ do emprego en Galicia se atopa en risco elevado de dixitalización, 2 puntos por enriba da media española.

Porén, esta cifra debe ser interpretada con cautela. En primeiro lugar, porque asume que todas as habilidades requiridas para desempeñar unha ocupación teñen a mesma facilidade para seren computarizadas, o que foi posto en dúbida na literatura ${ }^{6}$. E, en

\footnotetext{
4 O cálculo da probabilidade de automatización de cada ocupación por parte de Frey e Osborne (2017) realizouse en dúas etapas. Na primeira, un grupo de expertos valorou entre 70 ocupacións representativas cales poderían ser completamente automatizadas a medio prazo. Na segunda, utilizáronse os resultados da primeira etapa e a información sobre as características e tarefas de cada ocupación -proporcionada pola base de datos O*NET- para estimar a probabilidade de automatización do conxunto de ocupacións (702).

${ }^{5}$ Para iso emparellouse a clasificación de ocupacións utilizada por Frey e Osborne (2017), Standard Occupational Classification 2010 (SOC2010), coa CNO2011 mediante unha dupla correspondencia. A primeira, entre a SOC2010 e a International Standard Classification of Occupations 2008 (ISCO-08) e a segunda, entre esta e a CNO2011.

${ }^{6}$ Por exemplo, Arntz, Gregory e Zierahn (2016).
} 
segundo lugar, porque fai referencia ao risco de automatización 'de primeira rolda', causado pola viabilidade tecnolóxica, pero non incorpora o 'de segunda rolda', relacionado coa conveniencia económica de automatizar unha ocupación?.

En liña coa evidencia para outros países ${ }^{8}$, aprecíase que a distribución do emprego se atopa polarizada, tanto en Galicia como no conxunto de España (véxase o Gráfico 1). Nun extremo sitúanse aquelas ocupacións ligadas á dirección, á enxeñaría, ao ensino ou á saúde, menos expostas ao risco de automatización. Noutro atópanse aquelas tarefas máis rutineiras, como as administrativas ou as asociadas á construción ou ao sector primario, susceptibles de poder seren desenvolvidas por máquinas.

Malia que a porcentaxe de ocupados en risco en Galicia é semellante á de Finlandia ${ }^{9}$ (35\%) e menor cá de EE. UU.10 (47\%) ou Alemaña ${ }^{11}$ (59\%), a evolución recente do emprego en Galicia non deixa lugar á compracencia. Durante a crise, as ocupacións con media ou baixa probabilidade de automatización concentraron case o $60 \%$ do emprego destruído. Durante a recuperación, tan só explican a metade do emprego creado (véxase o Gráfico 2).

Gráfico 1 Distribución do emprego por ocupación conforme á súa probabilidade de automatización (media 2011-2016)

Galicia

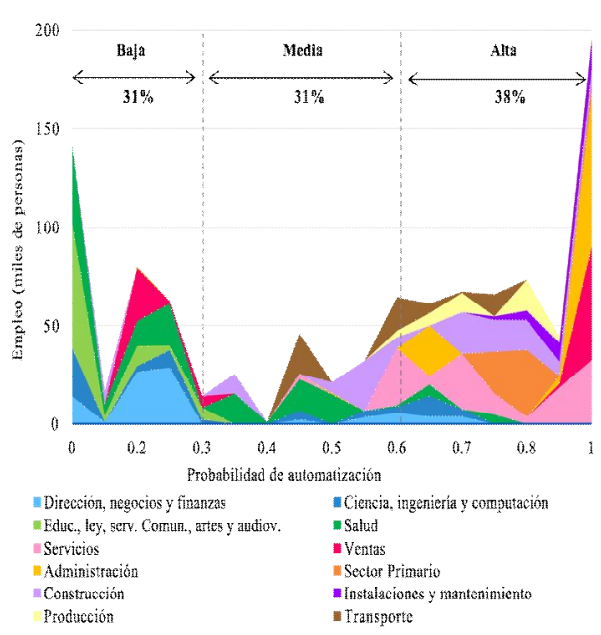

España

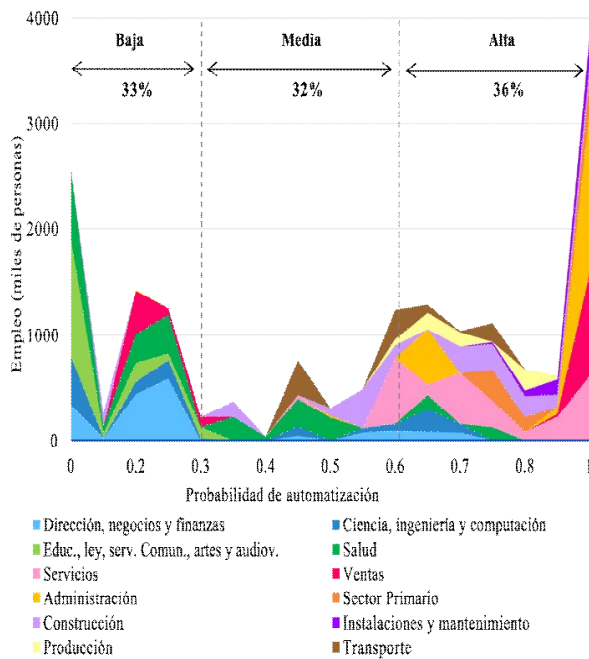

Fonte: elaboración propia a partir de Frey e Osborne (2017) e INE

${ }^{7}$ Como destaca Autor (2013).

8 Véxanse Goos, Manning e Salomons (2009), Autor e Dorn (2013), Dauth (2014) e Autor (2015).

${ }^{9}$ Véxase Pajarinen e Rouvinen (2014).

10 Véxase Frey e Osborne (2017).

11 Conforme ás estimacións de Brzeski e Burk (2015). 
Gráfico 2 Evolución do emprego conforme á súa probabilidade de automatización (contribución á variación acumulada, \%)

\section{Galicia}

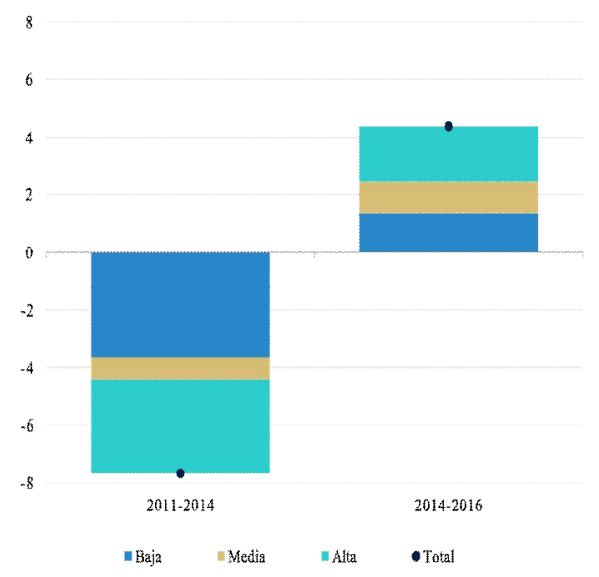

España

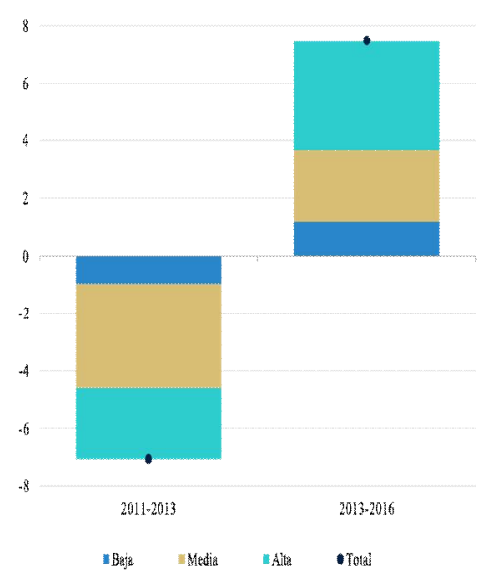

Fonte: elaboración propia a partir de Frey e Osborne (2017) e INE

Cales son os ocupados máis vulnerables ao avance da robotización? A análise descritiva, sintetizada no Cadro 1, suxire que a probabilidade de computarización baixa co nivel educativo, o grao de responsabilidade ${ }^{12}$ e o desenvolvemento de actividades ligadas á educación ou á saúde ${ }^{13}$.

Con respecto a isto, existe evidencia ${ }^{14}$ que amosa como un maior nivel educativo permite adquirir habilidades en áreas nas que as capacidades humanas aínda superan ás máquinas, o que favorece a complementariedade entre o capital e o traballo e a creación de novas oportunidades de emprego.

Ademais, o risco de automatización é maior para os traballadores que non participan en accións de formación non regrada. Dado que o impacto da tecnoloxía probablemente acurtará a vida útil das habilidades dos traballadores e que os novos modelos de negocio implicarán cambios continuos das competencias demandadas ${ }^{15}$, a importancia da formación continua -regrada e non regrada- como paliativo do risco de dixitalización aumentará no futuro.

\footnotetext{
12 En liña con Arntz, Gregory e Zierahn (2016).

13 Baumol et al. (2012) amosan que as sociedades máis acomodadas demandan máis servizos intensivos en traballo especializado.

${ }^{14}$ Véxase Autor e Dorn (2009).

15 Véxase WEF (2016).
} 
Cadro 1 Caracterización dos ocupados conforme á probabilidade de automatización da ocupación que realizan (media 2011-2016)

\begin{tabular}{|c|c|c|c|c|c|}
\hline & & \multicolumn{2}{|c|}{ Probabilidad de automatiaeibn } & \multicolumn{2}{|c|}{ Distribueibin de les asupados (\%) } \\
\hline & & Galicia & Espania & Galicia & Espafas \\
\hline Total & & 0.529 & 0.523 & & \\
\hline \multirow{4}{*}{ Ldad tn alios (cuartilas) } & Menos de 29 ahlos & 0.561 & 0.557 & 25.2 & 27.7 \\
\hline & 29. 38 & 0.527 & 0.515 & 24.5 & 25.4 \\
\hline & $38-46$ & 0.517 & 0.520 & 23.2 & 22.4 \\
\hline & Mas de 56 atlos & 0.311 & 0.493 & 27.1 & 24.6 \\
\hline \multirow[t]{2}{*}{ Gênero } & Varón & 0.522 & 0.522 & 53.0 & 54.4 \\
\hline & Misief & 0.336 & 0.524 & 47.0 & 45.6 \\
\hline \multirow{2}{*}{ Nacionalidad } & Españala & 0.526 & 0.511 & 96.4 & 88.7 \\
\hline & Exiranjera & 0.601 & 0.614 & 3.6 & 11.3 \\
\hline \multirow{7}{*}{$\begin{array}{l}\text { Nivei cducativo } \\
\text { (mixximo sicanrado) }\end{array}$} & Primaria & 0.660 & 0.658 & 5.9 & 7.8 \\
\hline & I' ctapa secundaria & 0.646 & 0.649 & 32.4 & 26.5 \\
\hline & $2^{4}$ etaps secundaris o superior en resto setotes & 0.517 & 0.517 & 45.7 & 49.3 \\
\hline & $2^{2}$ etapa secundaria en efacación, salud o serv, seciales & 0.450 & 0.441 & 1.6 & 1.8 \\
\hline & 2' etupa de sesunduria en STEM & 0.606 & 0.617 & 0.2 & 0.3 \\
\hline & Superior en ctacacibon, salud o servicies seciales & 0.208 & 0.204 & 10.2 & 9.6 \\
\hline & Superior en STLM & 0.371 & 0.355 & 4.1 & 4.7 \\
\hline \multirow{2}{*}{ Educación ho fregiada } & No & 0.540 & 0.535 & 91.7 & 91.1 \\
\hline & 5 & 0.405 & 0.404 & 8.3 & 8.9 \\
\hline \multirow{2}{*}{ Situacibe profesional } & Trabajador por eventa ajena & 0.339 & 0.941 & 79.1 & 83.6 \\
\hline & Trabajador por cuenta propia & 0.487 & 0.429 & 20.9 & 16.4 \\
\hline \multirow{2}{*}{$\begin{array}{l}\text { Sector } \\
\text { (sólo asalariados) }\end{array}$} & Asalatiados del sector privade & 0.604 & 0.59 .4 & 77.1 & 79.8 \\
\hline & Asalariabos del rector päblico & 0.323 & 0.333 & 22.9 & 20.2 \\
\hline \multirow{2}{*}{$\begin{array}{l}\text { Tipo de conatrato } \\
\text { (wolo assalariados) }\end{array}$} & Indefinido & 0.533 & 0.520 & 76.8 & 75.3 \\
\hline & Temporal & 0.561 & 0.579 & 23.2 & 24.8 \\
\hline \multirow{12}{*}{$\begin{array}{l}\text { Clasificación nacional de } \\
\text { ocupuciones }\end{array}$} & Dinectión, negocios $y$ finanras & 0.253 & 0.250 & s. 7 & 10.1 \\
\hline & Ciescia, ingenierila y computación & 0.297 & 0.301 & 6.2 & 7.1 \\
\hline & Edusación, ley, serv. somunidad, artes y asdiov. & 6.091 & 0.093 & 8.5 & 8.6 \\
\hline & Salad & 0.259 & 0.270 & 13.6 & 13.5 \\
\hline & Servicios & 0.732 & 0.723 & 12.8 & 13.8 \\
\hline & Vencas & 0.664 & 0.666 & 9.2 & 8.9 \\
\hline & Adminisistración & 0.827 & 0.827 & 10.7 & 12.4 \\
\hline & Sector primario & 0.759 & $0.80 \mathrm{t}$ & 6.0 & 4.2 \\
\hline & Construeción & 0.613 & 0.607 & 11.8 & 10.1 \\
\hline & Instalación y mansenimiento & $0.84 !$ & 0.850 & 3.2 & 2.8 \\
\hline & Panduceib́n & 0.715 & 0.697 & 4.0 & 3.5 \\
\hline & Transporte & 0.541 & 0.543 & 5.4 & 4.9 \\
\hline \multirow{20}{*}{$\begin{array}{l}\text { Clasificación nucional de } \\
\text { actividades cconómicas }\end{array}$} & Sectist primatio & 0.730 & 0.770 & 6.3 & 4.0 \\
\hline & Industrias extroctivas & 0.595 & 0.564 & 0.5 & 0.2 \\
\hline & Industrias manufactureras & 0.640 & 0.623 & 14.2 & 12.7 \\
\hline & Suministo de encrgia & 0.490 & 0.438 & 0.4 & 0.5 \\
\hline & Sumunistro de agua, saneamiento & 0.597 & 0.581 & 0.6 & 0.8 \\
\hline & Construectón & 0.553 & 0.544 & 7.2 & 6.2 \\
\hline & Comercio y reparación de vehiculos de motor & 0.590 & 0.596 & 16.7 & 16.3 \\
\hline & Transporte y almacenamieato & 0.560 & 0.584 & 4.5 & 4.9 \\
\hline & Ilostcleria & 0.767 & 0.726 & 6.5 & 7.9 \\
\hline & $\mathrm{TnC}$ & 0.415 & 0.390 & 2.2 & 3.1 \\
\hline & Actividades financieras y de seguros & 0.579 & 0.580 & 2.0 & 2.6 \\
\hline & Actividades inmobiliarias & 0.536 & 0.562 & 0.3 & 0.6 \\
\hline & Aetividades profestonaies, eientificas y ternicas & 0.387 & 0.386 & 4.2 & 5.0 \\
\hline & Actividades administrativas & 0.603 & 0.594 & 4.2 & 5.2 \\
\hline & Administracionss püblisas & 0.448 & 0.454 & 6.6 & 7.0 \\
\hline & Educaciön & 0.167 & 0.169 & 7.2 & 6.9 \\
\hline & Actividades sanitarias y servictos seciales & 0.274 & 0.273 & 8.1 & 8.2 \\
\hline & Actividades artisticas & 0.417 & 0.477 & 1.9 & 1.9 \\
\hline & Otros servicios & 0.406 & 0.417 & 2.8 & 2.3 \\
\hline & Actividsdes del hogar & 0.635 & 0.629 & 3.4 & 3.7 \\
\hline
\end{tabular}

(Continúa en la página siguiente) 


\begin{tabular}{|c|c|c|c|c|c|}
\hline & & & & \multicolumn{2}{|c|}{ Cadro 1. Continuación } \\
\hline & & \multicolumn{2}{|c|}{ Probabilidad media (2011-2016) } & \multicolumn{2}{|c|}{ Distribueión de los ocupados (\%) } \\
\hline & & Galicia & Espața & Galicia & Espat̃a \\
\hline \multirow{4}{*}{$\begin{array}{l}\text { Antigüedad en la empresa } \\
\text { (cuartilas) }\end{array}$} & Menos de 9 meses & 0.578 & 0.583 & 21.7 & 25.0 \\
\hline & 9 meses-5 at̃os & 0.545 & 0.527 & 23.1 & 25.0 \\
\hline & 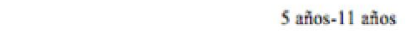 & 0.532 & 0.511 & 26.7 & 25.1 \\
\hline & Más de 11 at̃os & 0.475 & 0.470 & 28.6 & 24.9 \\
\hline \multirow{7}{*}{ Trabajadores a cargo } & Ninguno & 0.569 & 0.575 & 67.2 & 69.6 \\
\hline & Encargado, jefe de taller/oficina, capataz o similar & 0.447 & 0.471 & 7.1 & 6.3 \\
\hline & Mando intermedio & 0.339 & 0.339 & 4.1 & 6.1 \\
\hline & Diretor de peq. empresa, depart. o sucursal & 0.375 & 0.326 & 7.8 & 6.6 \\
\hline & Director de empresa grande o media & 0.252 & 0.225 & 0.5 & 0.8 \\
\hline & Ocupado independ. (sin jefes ni subordinados) & 0.530 & 0.459 & 13.1 & 10.5 \\
\hline & $\mathrm{Ns} / \mathrm{Ne}$ & 0.475 & 0.389 & 0.1 & 0.2 \\
\hline \multirow{4}{*}{$\begin{array}{l}\text { Trabajó en su domicilio en las } 4 \\
\text { últimas semanas }\end{array}$} & No teletrabaja & 0.546 & 0.543 & 92.9 & 92.3 \\
\hline & Ocasionalmente & 0.320 & 0.297 & 2.5 & 2.8 \\
\hline & Más de la mitad de las dias que trabajó & 0.288 & 0.264 & 3.8 & 4.0 \\
\hline & $\mathrm{Ns} / \mathrm{Nc}$ & 0.327 & 0.295 & 0.8 & 0.9 \\
\hline \multirow{3}{*}{ Tamaño del establecimiento } & $\mathrm{N} / \mathrm{Ne}$ & 0.554 & 0.564 & 5.5 & 6.3 \\
\hline & 1-10 empleados & 0.569 & 0.555 & 46.4 & 40.5 \\
\hline & Mád de 10 empleados & 0.487 & 0.494 & 48.1 & 53.2 \\
\hline \multirow{5}{*}{ Situación laboral hace un at̃o } & Ocupado & 0.524 & 0.514 & 92.1 & 90.1 \\
\hline & Parado & 0.608 & 0.626 & 5.8 & 7.0 \\
\hline & Estudiando & 0.521 & 0.545 & 1.3 & 1.5 \\
\hline & Inactivo & 0.549 & 0.555 & 0.5 & 1.1 \\
\hline & Otros & 0.602 & 0.646 & 0.4 & 0.4 \\
\hline \multirow{4}{*}{$\begin{array}{l}\text { Búsqueda de empleo en las } 4 \\
\text { últimas semanas }\end{array}$} & No buscó & 0.526 & 0.519 & 94.8 & 92.9 \\
\hline & $\mathrm{Si}$, más adecuado y estable & 0.576 & 0.593 & 1.7 & 1.9 \\
\hline & $\mathrm{Si}$, mís ingresos mejor horario & 0.586 & 0.579 & 3.2 & 4.7 \\
\hline & $\mathrm{Si}$, otros motivos & 0.563 & 0.561 & 0.3 & 0.5 \\
\hline \multirow{17}{*}{ Comunidad Autónoma } & Andalucía & & 0.536 & & 15.2 \\
\hline & Aragón & & 0.529 & & 3.0 \\
\hline & Asturias, Principado de & & 0.512 & & 2.2 \\
\hline & Balears, Illes & & 0.546 & & 2.8 \\
\hline & Canarias & & 0.557 & & 4.3 \\
\hline & Cantabria & & 0.524 & & 1.3 \\
\hline & Castilla y León & & 0.529 & & 5.3 \\
\hline & Castilla-La Mancha & & 0.536 & & 4.1 \\
\hline & Cataluña & & 0.525 & & 17.5 \\
\hline & C. Valenciana & & 0.535 & & 10.4 \\
\hline & Extremadura & & 0.535 & & 2.0 \\
\hline & Galicia & 0.529 & 0.529 & 100.0 & 5.8 \\
\hline & Madrid, Comunidad de & & 0.477 & & 15.8 \\
\hline & Murcia, Región de & & 0.552 & & 3.0 \\
\hline & Navarra, Comunidad Foral de & & 0.530 & & 1.5 \\
\hline & Pais Vasco & & 0.507 & & 5.1 \\
\hline & Rioja, La & & 0.530 & & 0.7 \\
\hline
\end{tabular}


A análise da información da EPA tamén indica que a probabilidade de automatización é comparativamente elevada entre a mocidade, pero que apenas discorda por xénero. Con respecto a isto, a literatura ${ }^{16}$ atopa que as ocupacións en declive 'avellentan', é dicir, o risco de computarización aumenta coa idade media da forza laboral na devandita ocupación debido a que os traballadores máis lonxevos teñen menos incentivos a cambiar de rúbrica (ou máis dificultades para facelo). En canto ao xénero, a evidencia empírica17 decátase de que as mulleres -malia a súa infrarrepresentación en ocupacións STEM (OCDE, 2017)- atópanse mellor posicionadas cós homes para arrostrar o risco de dixitalización dada a súa maior presenza en ocupacións cualificadas ligadas á saúde ou á educación.

Por último, obsérvase que a probabilidade de automatización é maior para os asalariados - sobre todo, aqueles que teñen un contrato temporal ou traballan no sector privado-, os ocupados na agricultura, a industria manufactureira, a hostalería, o comercio, as actividades do fogar e as administrativas, e os que procuran outro posto de traballo ou estiveran desempregados con anterioridade. Como se aprecia no Cadro 1, a heteroxeneidade rexional é escasa. O risco de automatización é comparativamente elevado na Rexión de Murcia e nos arquipélagos (Baleares e Canarias) e reducido na Comunidade de Madrid, Asturias e o País Vasco.

\section{Determinantes da probabilidade de automatización}

Para distinguir as características que inflúen en que un traballador estea empregado nunha ocupación con maior risco de automatización, realízase unha análise de regresión. En particular, o modelo formula que a probabilidade de computarización da ocupación dun traballador depende das súas características persoais (xénero, idade, nivel educativo, etc.), laborais (situación profesional, tipo de contrato, antigüidade na empresa, grao de responsabilidade, etc.) e da empresa na que presta os seus servizos (tamaño e sector de actividade)..$^{18}$

Xa que a variable dependente (p) toma valores entre 0 e 1, estímase un modelo lineal xeneralizado (GLM) por máxima verosimilitude que asume unha distribución loxística de p. ${ }^{19}$ O Cadro 2 sintetiza os resultados das estimacións. En concreto, ilustra os efectos marxinais das categorías de resposta de cada variable con respecto á categoría de referencia.

A variable que xera maiores diferenzas no risco de automatización entre traballadores é o sector de actividade. En termos xerais, os ocupados no sector servizos teñen unha menor probabilidade de ser substituídos por máquinas cós da industria ou da agricultura. Pero a heteroxeneidade no sector terciario é notable. Como sinala o Cadro 2, o risco de computarización é comparativamente reducido para os ocupados en actividades ligadas á educación, á arte, á saúde e aos servizos sociais, e mais para os que traballan na administración pública e nos sectores TIC, enerxético e científico-técnico. No extremo oposto atópanse os empregados na agricultura, a hostalería, a industria manufactureira, as actividades financeiras e inmobiliarias e o comercio.

\footnotetext{
16 Véxase Autor e Dorn (2009).

17 Véxanse Autor e Dorn (2009), Anghel, De la Rica e Lacuesta (2013) ou OCDE (2017b), entre outros.

18 Malia que o modelo estima a probabilidade de que un traballador con determinadas características estea empregado nunha ocupación cun certo risco de automatización, non implica a existencia dunha relación causal nun senso estrito.

${ }^{19}$ En liña con Papke e Wooldridge (1996).
} 
Entre as características do posto de traballo, destaca a importancia da posición xerárquica. O Cadro 2 indica que a probabilidade de dixitalización baixa co nivel de responsabilidade. Así, o risco de que un director de empresa sexa substituído por unha máquina é 26 puntos menor, ceteris paribus, có dun ocupado sen traballadores a cargo (20 puntos no conxunto de España). A adopción de novas formas de traballo tamén contribúe a reducir a vulnerabilidade á automatización ${ }^{20}$, o que suxire que a capacidade de adaptación do traballador (e da empresa) pode compensar o risco de robotización. Así, a probabilidade de que un ocupado que teletraballa perda o seu emprego é 10 puntos menor cá de quen non o fai.

En liña cos resultados da análise descritiva e a evidencia empírica ${ }^{21}$, constátase que o nivel educativo é unha das variables fundamentais para explicar as diferenzas na probabilidade de computarización. Os traballadores máis formados -sobre todo, os titulados universitarios en disciplinas relacionadas coa educación, a saúde e os servizos sociais- e os que participaron en accións formativas non regradas ${ }^{22}$ teñen menos risco de ser substituídos por máquinas. Cuando se diferencia por xénero, aprecíase que a probabilidade de automatización das mulleres é maior cá dos homes con independencia do nivel educativo. Tan só as mulleres con titulación secundaria nunha rama sociosanitaria teñen un menor risco de dixitalización cós homes.

As restantes variables teñen un efecto menor sobre a probabilidade de computarización. En relación coas características da empresa, estímase que o risco de ser substituído por unha máquina é máis reducido no sector público e nos establecementos de maior dimensión.

Con respecto ás características do traballador, obtense que a probabilidade de automatización descende coa idade e é lixeiramente máis elevada para os menores de 38 anos (28 anos no caso de España) ${ }^{23}$.

Ao contrario do que sinalaba a análise descritiva e as estimacións para o conxunto de España, os traballadores estranxeiros residentes en Galicia enfróntanse a unha probabilidade de dixitalización da súa ocupación semellante á dos nativos. O risco de computarización tampouco varía coa antigüidade do traballador na empresa ${ }^{24}$. Tan só os ocupados con maior antigüidade exhiben unha probabilidade de automatización máis elevada. Con respecto a isto, a literatura suxire que a maior vulnerabilidade dos ocupados con máis antigüidade podería estar reflectindo os seus menores incentivos para se adaptaren ao cambio tecnolóxico, o que os levaría a permanecer en ocupacións en declive ${ }^{25}$.

\footnotetext{
20 En liña coa evidencia apuntada por WEF (2016).

${ }^{21}$ Autor e Dorn (2009), Arntz, Gregory e Zierahn (2016) ou Gallego (2017).

22 Os asalariados reducen o seu risco de automatización ao cursar estudos non regrados relacionados co seu emprego actual. Pola contra, a probabilidade de computarización dos traballadores por conta propia é menor entre os que participan en accións formativas non regradas orientadas a cambiar de emprego.

${ }^{23}$ Arntz, Gregory e Zierahn (2016) tamén obteñen que o papel xogado pola idade é poco relevante.

${ }^{24}$ Ao diferenciar asalariados de traballadores por conta propia, Doménech et al. (2018) atopan que a probabilidade de automatización diminúe coa antigüidade do traballador por conta propia, o que podería estar captando certa autoselección: os autónomos que souberon reorientar o seu negocio ata actividades menos susceptibles de seren automatizables exhiben carreiras laborais máis prolongadas.

25 Véxase Anghel, De la Rica e Lacuesta (2013).
} 
Cadro 2 Determinantes da probabilidade de automatización. Efectos marxinais (pp, media 2011-2016)

\begin{tabular}{|c|c|c|}
\hline & \multicolumn{2}{|c|}{ Galicia } \\
\hline & Coeficiente & $\begin{array}{l}\text { Error estándar } \\
\text { robusto }\end{array}$ \\
\hline \multicolumn{3}{|l|}{ Caracteristicas del ocupado } \\
\hline \multicolumn{3}{|l|}{ Decilas de edad (ref. 16-28 años) } \\
\hline $29-32$ & 0.15 & 0.75 \\
\hline 33-35 & -0.95 & 0.76 \\
\hline $36-38$ & -0.82 & 0.74 \\
\hline $39-42$ & -1.24 & $0.69 *$ \\
\hline $43-45$ & -1.07 & 0.72 \\
\hline $46-48$ & -2.14 & $0.74 * *$ \\
\hline $49-52$ & -1.35 & $0.71 *$ \\
\hline $53-57$ & -1.92 & $0.72 * * *$ \\
\hline 58 años o más & -3.64 & $0.75 \cdots *$ \\
\hline \multicolumn{3}{|l|}{ Nacionalidad (ref. Española) } \\
\hline Extranjera & -1.78 & $0.95^{*}$ \\
\hline \multicolumn{3}{|l|}{ Género (ref. Hombre) } \\
\hline Mujer & 6.80 & $0.35 \cdots$ \\
\hline \multicolumn{3}{|l|}{ Nivel educativo (ref. Primaria) } \\
\hline $1^{*}$ etapa de secundaria & -1.40 & $0.56 *$ \\
\hline $2^{*}$ etapa de secundaria en educación, salud o servicios sociales & -5.57 & $1.90 * * *$ \\
\hline $2^{*}$ etapa de secundaria en STEM* & -3.16 & 2.78 \\
\hline $2^{4}$ etapa de secundaria o superior en resto sectores & -6.01 & $0.62 \ldots$ \\
\hline Superior en educación, salud o servicios sociales & -26.24 & $1.02 * *$ \\
\hline Superior en STEM* & -13.66 & $1,11 * *$ \\
\hline \multicolumn{3}{|l|}{ Mujer y nivel educativo (ref. Hombre con mismo nivel educativo) } \\
\hline Primaria & 0.51 & 1.02 \\
\hline $1^{*}$ ctapa de sccundaria & 5.14 & $0.52 \ldots$ \\
\hline $2^{4}$ etapa de secundaria o superior en resto sectores & 10.46 & $0.51 * *$ \\
\hline $2^{a}$ etapa de secundaria en educación, salud o servicios sociales & -5.84 & $3.35 *$ \\
\hline $2^{*}$ etapa de secundaria en STEM* & 2.94 & 5.48 \\
\hline Supcrior en educación, salud o servicios sociales & 4.79 & $1.41 * *$ \\
\hline Superior en STEM* & 1.54 & 1.82 \\
\hline
\end{tabular}

Superior en STEM*

Edueación no reglada (últimas 4 semanas)

(ref. Vinculada con ocupación actual, participa la empresa)

Vinculada con ocupación actual, no participa la empresa

Vinculada con ocupaciôn futura, participa la empresa

Vinculada con ocupación futura, no participa la empresa

(1)

\begin{tabular}{cc} 
España \\
\hline Coeficiente & $\begin{array}{c}\text { Error estándar } \\
\text { robusto }\end{array}$ \\
\hline
\end{tabular}

Por interés personal

No

\author{
(1)
}

Caracteristicas del puesto de trabaio

Situación profesional (ref. Asalariado indefinido del seetor público)

Asalariado temporal del sector público

Asalariado indefinido del sector privado

Asalariado temporal del sector privado

Empleado por cuenta propia

Decilas de antigüedad en la empresa (ref. <medio año)

$0,5-1,5$ años

$1,6 \cdot 3,2$

$3,3-5,2$

$5,3-7,5$

$7,6-10,3$

$10,4=14,0$

$14,1-19,7$

$19,8-26,7$

26,8 años o más

Trabajo desde el domicilio (ref. No teletrabaja)

Ocasionalmente

Más de la mitad de los dies que trabaióo

Trabajadores a cargo (ref. Ninguno)

Encargado, jefe de taller, capataz o similar

Mando intermedio

Director de pequeña empresa, departamento o sucursal

Director de empresa grande o media

Ocupado independiente ( $s$ in jefes ni subordinados)

ns/nc

Situación laboral hace 1 año (ref. Ocupado)

Parado

Estudiando

Inactivo

Otros

Búsqueda de empleo (ref. No busea)

Si, más estable $y$ adecuado a la formación

Si, mejores condiciones económicas y de horario

Si, otros motivos

(Continúa en la página siguiente)

\begin{tabular}{|c|c|}
\hline Coeficiente & robusto \\
\hline-1.76 & $0,33 * *$ \\
\hline-2.07 & $0.34 * 4 *$ \\
\hline-2.01 & $0.33 * * *$ \\
\hline$-2,00$ & $0,31 \cdots$ \\
\hline-1.84 & $0.33 *$ \\
\hline-1.58 & $0.33 \ldots$ \\
\hline-1.63 & $0.32 * * *$ \\
\hline-1.77 & $0.33 * * *$ \\
\hline-3.61 & $0.35 \cdots$ \\
\hline 0.98 & $0.28 * * *$ \\
\hline 5.63 & $0.15 \ldots$ \\
\hline 0.01 & 0.24 \\
\hline-6.80 & $0.74 * 4 *$ \\
\hline 1.11 & 1.35 \\
\hline-4.99 & $0.25 *$ \\
\hline-25.13 & $0.44 * \ldots$ \\
\hline$-14,80$ & $0.46 \div 4 *$ \\
\hline-0.29 & 0.41 \\
\hline 3.69 & $0.25 \ldots$ \\
\hline 8.70 & $0.22 * 4$ \\
\hline-1.11 & 1.27 \\
\hline 6.54 & $2.75 * *$ \\
\hline 3.71 & $0.63 \ldots$ \\
\hline 2.45 & $0.76 * 4$ \\
\hline
\end{tabular}

\begin{tabular}{rl} 
& \\
-3.77 & $0.35 \cdots *$ \\
-7.30 & $0.66 \cdots$ \\
2.05 & 2.46 \\
1.93 & $0.67 \cdots *$ \\
-1.54 & $0.63 \cdots$ \\
\hline
\end{tabular}

\begin{tabular}{ll} 
& \\
\hline & \\
& \\
3.59 & 0.44 \\
2.65 & $0.36 * *$ \\
& $0.42 * * *$
\end{tabular}

\begin{tabular}{ll}
2.65 & $0.42 * \cdots$ \\
0.55 & 0.52 \\
\hline 0.67 & $0.32 \cdots$
\end{tabular}

$\begin{array}{ll}-0.67 & 0.32 * \\ -0.56 & 0.36\end{array}$

$\begin{array}{ll}-0.56 & 0.36 \\ -0.49 & 0.37\end{array}$

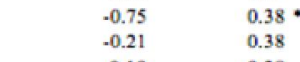

$\begin{array}{ll}0.10 & 0.38\end{array}$

$\begin{array}{ll}0.45 & 0.39 \\ 1.52 & 0.39\end{array}$

\begin{tabular}{rr}
1.52 & $0.39 * * *$ \\
1.54 & $0.40 * * *$ \\
\hline
\end{tabular}

\begin{tabular}{rr}
\hline $\begin{array}{r}-7.63 \\
-8.96\end{array}$ & $0.46 \cdots$ \\
& $0.43 * *$ \\
\hline 11.03 & $1.81 \cdots$
\end{tabular}

\begin{tabular}{rl}
11.03 & $1.81 * *$ \\
-0.77 & $1.84 \ldots$ \\
-5.69 & $1.85 * *$ \\
-14.24 & $1.84 * *$ \\
-20.80 & $1.97 * *$ \\
-4.02 & $1.85 * *$ \\
\hline & \\
1.60 & $0.31 * *$ \\
-1.24 & $0.66 *$ \\
1.13 & $0.67 *$ \\
0.15 & 0.91 \\
\hline & \\
1.55 & $0.49 * * *$ \\
-0.62 & $0.33 *$ \\
0.04 & 0.95 \\
\hline
\end{tabular}


Cadro 2 Determinantes da probabilidade de automatización. Efectos marxinais (pp, media 2011-2016) (Continuación)

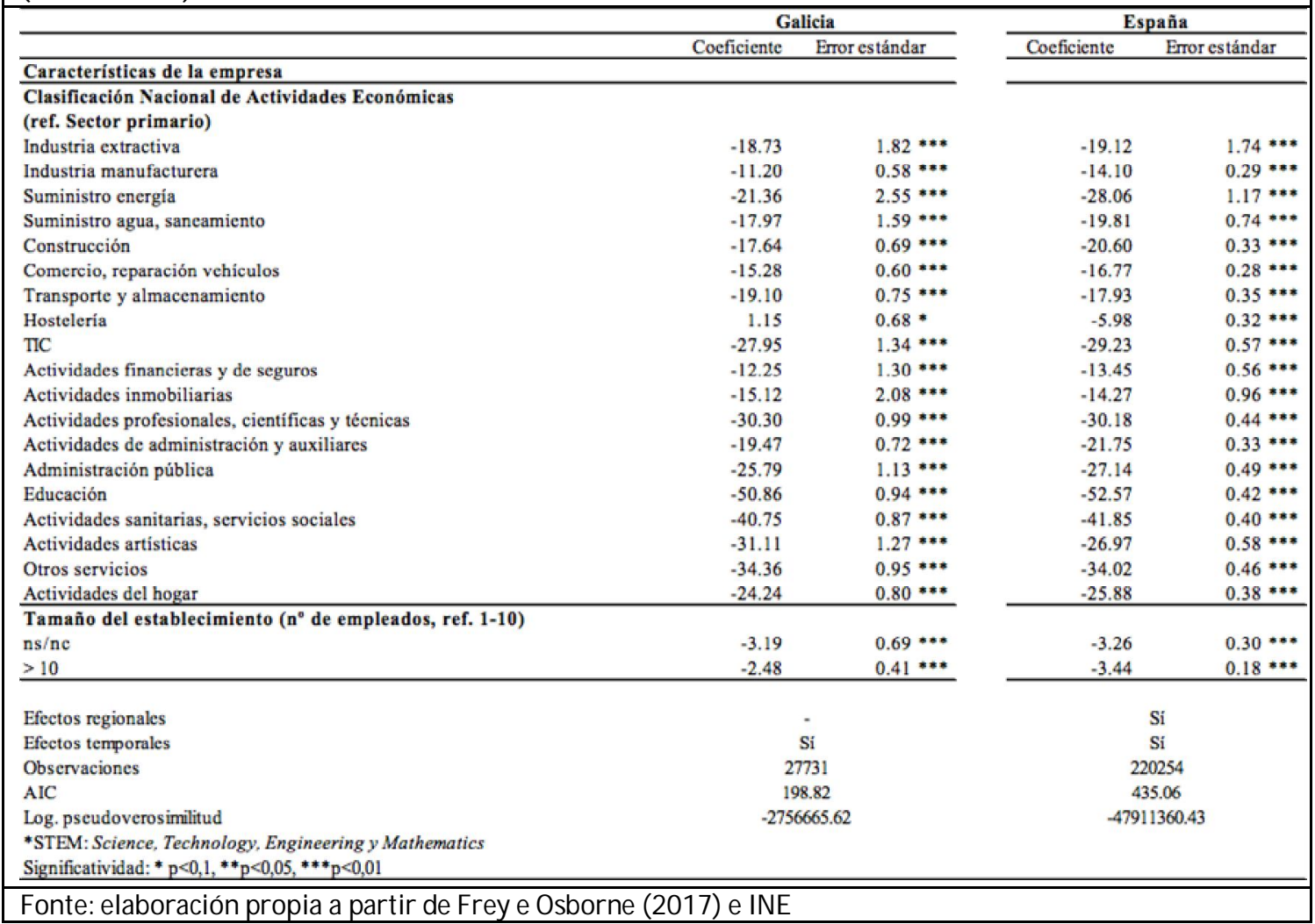

\section{Conclusións}

Todas as revolucións industriais tiveron repercusións notables sobre o mercado de traballo, e a actual non representa unha excepción. O proceso de transformación dixital en curso e os avances en robótica e intelixencia artificial crearán novos empregos, tanto nos sectores innovadores como naqueles beneficiados polo efecto renda ocasionado polo cambio tecnolóxico. Porén, a Cuarta Revolución Industrial tamén precipitará a automatización de numerosas tarefas, o que podería poñer en risco ata un 38\% dos postos de traballo actualmente existentes en Galicia, dous puntos máis cá media de España.

Malia que este proceso de destrución creativa non constitúe un aspecto sobranceiro do cambio tecnolóxico actual, a velocidade que está acadando a actividade innovadora si que o é, e ameaza con abreviar o percorrido cara un novo equilibrio entre a oferta e a demanda de emprego. Como consecuencia, a identificación dos traballadores máis vulnerables á revolución dixital é unha condición necesaria para minimizar os custos de transición individuais e sociais.

A partir das probabilidades de automatización de cada ocupación obtidas por Frey e Osborne (2017), utilízanse os microdatos da mostra anual da EPA entre 2011 e 2016 para determinar as características persoais e laborais que condicionan o risco de que un traballador en Galicia sexa substituído por unha máquina. Os resultados das estimacións amosan que a probabilidade de automatización diminúe co grao de responsabilidade, 0 nivel educativo, a disposición a participar en accións formativas e adopción de novas formas de traballo -como o teletraballo-, e é comparativamente reducida para os 
ocupados en educación, sanidade, servizos sociais, TIC, enerxía e actividades artísticas ou científico-técnicas. As restantes características do traballador - como o xénero, a idade, a nacionalidade, a antigüidade, o tipo de contrato ou a situación laboral de procedencia- e da empresa -como o tamaño- xogan un papel secundario para explicar o risco de dixitalización.

Co obxectivo de atenuar as repercusións negativas do progreso tecnolóxico sobre o emprego e acadar un crecemento inclusivo, é imprescindible que os axentes económicos, tanto públicos como privados, gobernen o cambio. Para acadalo, é preciso actuar en dous ámbitos estreitamente relacionados: a educación e o mercado de traballo.

En primeiro lugar, resulta esencial investir máis e mellor en capital humano para que a poboación adquira coñecementos e habilidades cognitivas e non cognitivas complementarias ao progreso técnico. Ademais, nun contexto de prolongación das carreiras laborais e de cambio tecnolóxico, apostar pola formación continua é unha obriga para os individuos, as empresas e o sector público. Para iso, é necesario anticipar as necesidades formativas e aumentar a flexibilidade do sistema educativo.

En segundo lugar, é ineludible mellorar a eficacia e a eficiencia das políticas do mercado de traballo, tanto das activas - que se deberán orientar cara a reciclaxe profesional- como das pasivas -que deberán ampliar a súa cobertura durante o período de transición-. Coa finalidade de optimizar os emparellamentos laborais e acurtar o tempo de permanencia no paro, os servizos públicos de emprego deben utilizar a tecnoloxía xa dispoñible para explotar grandes bases de datos que recompilan información sobre as necesidades das empresas e as características dos traballadores. Paralelamente, dada a expansión dos modelos de negocio baseados en plataformas e das novas formas de contratación, é aconsellable reconsiderar a regulación laboral vixente ${ }^{26}$.

\section{Referencias}

Acemoglu, D., y Restrepo, P. (2017), "Robots and Jobs: Evidence from US Labor Markets", National Bureau of Economic Research, Working Paper No. 23285.

Anghel, B., De la Rica, S., y Lacuesta, A. (2013), "Employment Polarisation in Spain over the course of the 1997-2012 cycle”, Banco de España, Documentos de Trabajo № 1321.

Arntz, M., Gregory, T. y Zierahn, U. (2016), "The Risk of Automation for Jobs in OECD Countries: A Comparative Analysis”, OECD Social, Employment and Migration Working Papers No. 189, OECD Publishing, Paris.

Arulampalam, W. (2001), "Is Unemployment Really Scarring? Effects of Unemployment Experiences on Wages", Economic Journal, 111 (475), F585-F606.

Autor, D. (2013), "The 'task approach' to labor markets: an overview”, Journal for Labour Market Research, 46(3), 185-199.

Autor, D. y Dorn, D. (2009), "This Job is 'Getting Old': Measuring Changes in Job Opportunities Using Occupational Age Structure”, American Economic Review: Papers and Proceedings, 99(2), 45-51.

Autor, D. (2015), "Why are there still so many jobs? The history and future of workplace automation", The Journal of Economic Perspectives, 29(3), 3-30.

Autor, D. y Dorn, D. (2013), "The Growth of Low-Skill Service Jobs and the Polarization of the US Labor Market”, American Economic Review, 103(5), 1553-97.

Avent, R. (2017), The Wealth of Humans. Work and Its Absence in the Twenty-first Century. Penguin.

${ }^{26}$ Unha proposta ao respecto é a de Harris e Krueger (2015). 
Baumol, W., Ferranti, D., Malach, M., Pablos-Méndez, A., Tabish, H. Y Gomory, L. (2012), The Cost Disease: Why Computers Get Cheaper and Health Care Doesn't. New Haven: Yale University Press.

Brzeski, C. y Burk, I. (2015), "The Robots Come. Consequences of Automation for the German Labour Market”, ING DiBa Economic Research.

Dauth, W. (2014), “Job Polarization on Local Labor Markets”, IAB Discussion Paper n. 18.

Doménech, R., García, J. R., Montañez, M. y Neut, A. (2018), "Afectados por la revolución digital: el caso de España”, de próxima aparición en Papeles de Economía Española.

Frey, C y Osborne, M.A. (2017), "The Future of Employment: How Susceptible are Jobs to Computerization?”, Technological Forecasting and Social Change, vol. 114(C), 254-280.

Gallego, A. (2017), “Ocupaciones en transformación: ¿A quién afectará el cambio tecnológico?", Observatorio Social de la Caixa.

Goos, M., Manning, A. y Salomons, A. (2009), "Job Polarization in Europe”, American Economic Review: Papers and Proceedings, 99 (2), 58-63.

Graetz, G. y Michaels. G. (2018), "Robots at Work”, mimeo, LSE.

Gregory, T., Salomons, A. y Zierahn, U. (2016), "Racing With or Against the Machine? Evidence from Europe", ZEW Centre for European Economic Research, Discussion Paper No. 16-053.

Harris, S. y Krueger, A. (2015), “A Proposal for Modernizing Labor Laws for Twenty-First Century Work: The Independent Worker", The Hamilton Project, Discussion Paper 201510.

Mokyr, J., Vickers, C., y Ziebarth, N.L. (2015), "The history of technological anxiety and the future of economic growth: Is this time different?", The Journal of Economic Perspectives, 29(3), 31-50.

Moretti, E. (2010), “Local Multipliers”, American Economic Review, Papers and Proceedings, 100(2), 373-77.

OCDE (2017), Going Digital: The Future of Work for Women, OECD Publishing, Paris.

Pajarinen, M. y Rouvinen, P. (2014), “Computerization Threatens One Third of Finnish Employment", ETLA Brief, No. 22.

Papke, L. y Wooldridge, J.D. (1996), "Econometric Methods for Fractional Response Variables with an Application to 401(K) Plan Participation Rates", Journal of Applied Econometrics, Vol. 11 (6), 619-632

World Economic Forum (2016), The Future of Jobs Employment, Skills and Workforce Strategy for the Fourth Industrial Revolution, World Economic Forum, Davos.

Revista Galega de Economía: http://www.usc.es/econo/RGE/benvidag.htm 